\title{
Lifecourse socioeconomic circumstances and multimorbidity among older adults
}

Reginald D Tucker-Seeley ${ }^{1,2^{*}}$, Yi Li $^{3,4}$, Glorian Sorensen ${ }^{1,2}$ and SV Subramanian ${ }^{2}$

\begin{abstract}
Background: Many older adults manage multiple chronic conditions (i.e. multimorbidity); and many of these chronic conditions share common risk factors such as low socioeconomic status (SES) in adulthood and low SES across the lifecourse. To better capture socioeconomic condition in childhood, recent research in lifecourse epidemiology has broadened the notion of SES to include the experience of specific hardships. In this study we investigate the association among childhood financial hardship, lifetime earnings, and multimorbidity.

Methods: Cross-sectional analysis of 7,305 participants age 50 and older from the 2004 Health and Retirement Study (HRS) who also gave permission for their HRS records to be linked to their Social Security Records in the United States. Zero-inflated Poisson regression models were used to simultaneously model the likelihood of the absence of morbidity and the expected number of chronic conditions.

Results: Childhood financial hardship and lifetime earnings were not associated with the absence of morbidity. However, childhood financial hardship was associated with an 8\% higher number of chronic conditions; and, an increase in lifetime earnings, operationalized as average annual earnings during young and middle adulthood, was associated with a $5 \%$ lower number of chronic conditions reported. We also found a significant interaction between childhood financial hardship and lifetime earnings on multimorbidity.

Conclusions: This study shows that childhood financial hardship and lifetime earnings are associated with multimorbidity, but not associated with the absence of morbidity. Lifetime earnings modified the association between childhood financial hardship and multimorbidity suggesting that this association is differentially influential depending on earnings across young and middle adulthood. Further research is needed to elucidate lifecourse socioeconomic pathways associated with the absence of morbidity and the presence of multimorbidity among older adults.
\end{abstract}

\section{Background}

Chronic conditions generally cluster and individuals with one chronic condition are likely to have other conditions as well. As such, many older adults now manage two or more chronic conditions at the same time (i.e. multimorbidity) $[1,2]$; and evidence suggests that the presence of multimorbidity is expected to continue to rise [3-5]. The influence of childhood material conditions and lifetime earnings on multimorbidity has yet to be investigated. Considering the impending shift in the US population demographic as the baby-boomers reach age 65 , which will yield an elderly population characterized

\footnotetext{
* Correspondence: retucker@hsph.harvard.edu

${ }^{1}$ Center for Community Based Research, Dana-Farber Cancer Institute, 450 Brookline Ave, Boston, MA, 02215 USA

Full list of author information is available at the end of the article
}

by declining death rates, increasing life expectancy, and increasing health care costs, [6,7] an understanding of the correlates of multimorbidity in older adults is a crucial issue for population health research $[8,9]$.

\section{Lifecourse financial/economic conditions}

A substantial literature exists documenting the positive association between childhood SES and adult health[10]; specifically, low childhood socioeconomic status (e.g. parental occupation, parental educational attainment) has been linked to heart disease,[11] stroke [12], diabetes [13], and some cancers [14] among adults. A few lifecourse epidemiology studies have broadened the notion of childhood socioeconomic status (SES) to include specific financial hardships present in the socioeconomic environment during childhood [15-17]. For example,

\section{(Ciomed Central}


Lundberg (1997) found that respondents growing up in a family that experienced economic difficulties had an increased risk for circulatory illness in adulthood, even after controlling for demographic and socioeconomic characteristics and baseline health [17]. Additionally, Moody-Ayers, et al (2007) showed an independent effect of childhood financial hardship on functional limitations among older adults over and above the influence of adult SES and demographic characteristics [18].

Financial hardships in childhood can greatly influence subsequent access to financial/economic resources, $[19,20]$ which in turn affects the trajectory of health outcomes throughout the lifecourse [21]. As such, SES over the lifecourse has been shown to be more strongly associated with adult disease outcomes than an assessment of SES for a particular point in time [22,23]. In particular, cumulative disadvantage or low lifecourse SES has been shown to be positively associated with morbidity and mortality [24-27]. However, the relationship among childhood financial hardship, earnings across adulthood, and multimorbidity remains to be investigated; in particular, to our knowledge no study has been conducted to determine the association of these factors among older adults.

The aims for the present study were threefold. The first aim was to determine the association between childhood financial hardship and multimorbidity adjusting for demographic and socioeconomic characteristics. The second aim was to determine the association between lifetime earnings and multimorbidity; and the third aim was to determine if lifetime earnings act as an effect modifier in the association between childhood financial hardship and adult multimorbidity.

\section{Methods}

\section{Data source}

The Health and Retirement Study (HRS) is a national longitudinal study of the economic, health, marital, family status, and public/private support systems of older Americans funded by the National Institute on Aging and the Social Security Administration and conducted by the Institute for Social Research Survey Research Center at the University of Michigan [28]. The HRS uses a national multistage area probability sample of households in the U.S., with oversamples of Blacks, Hispanics, and residents from the state of Florida. Details of the HRS data collection methods are described elsewhere [29]. We used respondents from the 2004 wave of the HRS who signed consent forms for their social security earnings records to be linked to their HRS records $(\mathrm{N}=7,792)$. To determine lifetime earnings of the respondents, we linked the 2004 HRS public use dataset to the 2004 Permissions: Summary Earnings Information Restricted data set provided by the HRS. The 2004 Permissions data set includes earnings data for HRS respondents from 1951 to 2003. Subjects were dropped from analyses if they were under age $50(\mathrm{~N}=369)$, if they were missing data on the childhood financial hardship variable $(\mathrm{N}=37)$, and if they were missing data on the multimorbidity variable $(\mathrm{N}=61)$ or the socioeconomic variables $(\mathrm{N}=20)$. The final sample used for analysis was $\mathrm{N}=7,305$. The Institutional Review Board (IRB) at the University of Michigan approved the Health and Retirement Study and the Office of Human Research Administration at the Harvard School of Public Health approved this study.

\section{Outcome variable}

Multimorbidity was operationalized as the count of six chronic conditions reported in the 2004 HRS. The chronic conditions of interest were cancer, heart disease, lung disease, stroke, diabetes, and hypertension. Chronic conditions were assessed in the HRS by a series of questions where respondents were asked if a doctor had ever told them if they had one of these diseases.

\section{Primary predictor variables}

We operationalized childhood financial hardship with the dichotomous (yes/no) question from the HRS: 1) While you were growing up, before age 16, did financial difficulties ever cause you or your family to move to a different place?

We used average annual lifetime earnings during young and middle adulthood to operationalize lifetime earnings. Average annual lifetime earnings were calculated as the mean annual earnings of the respondent from age 20 to age 50 . We selected up to age 50 because this is the age of eligibility for the HRS, thus all respondents would potentially have earnings up to age 50 . Years with zero earnings were excluded from the calculation of average annual lifetime earnings to avoid misclassifying respondents who may temporarily leave the labor market (e.g. respondents with child-rearing responsibilities) [30]. Earnings were inflation-adjusted to 2003 US dollars using the consumer price index for urban consumers (CPI-U 1951-2003) [31]. For ease of interpretation, we divided average annual earnings by $\$ 10,000$ so that changes in the outcome would be associated with a $\$ 10,000$ change in average annual earnings.

\section{Covariates}

Educational attainment was used as an indicator of adult SES [32]. It was grouped into three categories: less than high school, high school diploma/GED, and some college or more.

Demographic characteristics such as gender, race (white/non-white), ethnicity (Hispanic/non-Hispanic), and age were assessed by self-report in the HRS. Tertiles were 
created for the age variable: 50-59, 60-69, and 70 and older for univariate and bivariate analysis.

\section{Statistical analysis}

In order to test the association among childhood financial hardship, average annual lifetime earnings, and multimorbidity, bivariate and multivariable tests were performed. Bivariate analyses using Wilcoxon-Mann-Whitney tests were conducted to determine differences in multimorbidity between demographic categories and Kruskall-Wallis tests were conducted to determine differences in multimorbidity across SES categories. Additionally, unadjusted rate ratios were estimated with robust standard errors to quantify differences across demographic and SES categories in multimorbidity.

To take into consideration the count nature of the outcome variable and the substantial number of respondents reporting no chronic conditions $(Y=0)$, zero-inflated Poisson (ZIP) regression was used [33] (30\% of respondents in this sample reported no chronic conditions). The ZIP model assumes that the respondents potentially come from two different distributions: one distribution that is indeed likely to have a zero count (no disease), and another distribution that follows the Poisson distribution (count of the six chronic conditions measured in this study) [34]. The ZIP model is a two-part model represented as: 1) $\mathrm{P}\left(y_{i} \mid x_{i}\right)=p_{i}+\left(1-p_{i}\right) \exp \left(-\mu_{i}\right)$ when $y_{i}=0$ and;2) $\mathrm{P}\left(y_{i} \mid x_{i}\right)=\frac{\left(1-p_{i}\right) \exp \left(-\mu_{i}\right) \mu_{i}^{\gamma_{i}}}{y_{i} !}$ when $y_{i} \geq 1$ [35]. The first part represents a logistic model that estimates the change in the log-odds of reporting no chronic conditions (absence of morbidity) for each one-unit change in the independent variable, and the second part represents a Poisson model that estimates the percentage change in the number of chronic conditions for a oneunit change in the independent variable. The justification for this approach is that the factors associated with having one or more chronic conditions might be differentially associated with the absence of morbidity (reporting no chronic conditions).

SAS $9.2^{\odot}$ was used for model building. Following bivariate analysis, we developed unadjusted models to evaluate the association between childhood financial hardship and multimorbidity in 2004 (Model 1). Next, we adjusted for demographic (Model 2) and socioeconomic characteristics (Model 3). We then developed unadjusted models to evaluate the association between lifetime earnings and multimorbidity in 2004 (Model 4). Next, we adjusted this model for demographic (Model 5) and socioeconomic characteristics (Model 6). We then entered average annual lifetime earnings into Model 3 to evaluate the influence of lifetime earnings on the childhood financial hardship adjusted model
(Model 7). To determine if the association between childhood financial hardship and multimorbidity was modified by lifetime earnings, we entered an interaction term (lifetime earnings $\times$ childhood financial hardship) into the model (Model 8) [36].

\section{Results}

Table 1 lists the descriptive statistics. The average age for the full sample was 65 years old. Nineteen percent of the sample reported childhood financial hardship. The mean number of chronic conditions was 1.24 , with $30 \%(\mathrm{~N}=$ $2,193)$ reporting no chronic conditions. The mean number of chronic conditions for those reporting childhood financial hardship was 1.35 and the mean number of chronic conditions for those reporting no childhood financial hardship was 1.20. The median average annual lifetime earnings up to age 50 (CPI-U adjusted) was $\$ 19,410$ with an inter-quartile range of $\$ 20,235$ (see Table 1).

Bivariate analysis suggests differences in multimorbidity across all demographic and socioeconomic categories except Hispanic ethnicity (see Table 1). Unadjusted rate ratios showed that men reported slightly higher multimorbidity than women. In particular, the expected number of chronic conditions in men was $8 \%$ higher than in women. For non-white respondents, the unadjusted expected number of chronic conditions was $21 \%$ higher compared to white respondents. The unadjusted expected number of chronic conditions for those age 60-69 and 70 and older was $56 \%$ and $85 \%$, respectively, greater than the respondents age 50-59. The unadjusted expected number of chronic conditions across education categories was $16 \%$ higher for those with educational attainment of high school/GED and 46\% higher for those with less than high school compared to the some college or more group of respondents. No statistically significant differences in multimorbidity were noted in Hispanic ethnicity; therefore, ethnicity was not included in subsequent models (see Table 2).

\section{Multivariable analysis: childhood financial hardship and multimorbidity}

The logistic portion of the unadjusted and adjusted ZIP regression models showed that childhood financial hardship was not significantly associated with the absence of morbidity (see Table 3, models 1-3, logistic portion). The Poisson portion of the unadjusted ZIP model showed that the expected number of chronic conditions for those reporting childhood financial hardship was 1.11 (CI: 1.04, 1.19) times that of those not reporting childhood financial hardship. After adjusting for gender, age, and race, the difference in expected number of chronic conditions between those 
Table 1 Frequency distributions for childhood financial hardship (CFH) and chronic conditions and bivariate associations between demographic and socioeconomic characteristics and multimorbidity

\begin{tabular}{|c|c|c|c|c|c|c|c|c|c|c|}
\hline & \multirow[b]{2}{*}{ N } & \multirow[b]{2}{*}{$\%$} & \multicolumn{2}{|c|}{$\begin{array}{c}\text { Childhood Financial } \\
\text { Hardship }\end{array}$} & \multicolumn{5}{|c|}{$\begin{array}{c}\text { Number of Chronic Conditions } \\
\text { (Multimorbidity) }\end{array}$} & \multirow[b]{2}{*}{ P-VALUE } \\
\hline & & & $C F H=0$ & $\mathrm{CFH}=1$ & 0 & 1 & 2 & 3 & 4 or more & \\
\hline Total & 7,305 & & 5,946 & 1,359 & 2,193 & 2,524 & 1,580 & 730 & 278 & \\
\hline Gender & & & & & & & & & & $p<.001$ \\
\hline Female & 3,916 & 53.61 & 3,244 & 672 & 1,238 & 1,382 & 769 & 374 & 153 & \\
\hline Male & 3,389 & 46.39 & 2,702 & 687 & 955 & 1,142 & 811 & 356 & 125 & \\
\hline Race & & & & & & & & & & $p<.001$ \\
\hline White & 5,907 & 80.87 & 4,827 & 1,080 & 1,861 & 2,053 & 1,241 & 550 & 202 & \\
\hline Non-white & 1,397 & 19.13 & 1,118 & 279 & 331 & 471 & 339 & 180 & 76 & \\
\hline Hispanic Ethnicity & & & & & & & & & & $p=.12$ \\
\hline Hispanic & 740 & 10.13 & 570 & 170 & 233 & 260 & 162 & 67 & 18 & \\
\hline Non-Hispanic & 6,565 & 89.87 & 5,376 & 1,189 & 1,960 & 2,264 & 1,418 & 663 & 260 & \\
\hline \multicolumn{11}{|l|}{ Age } \\
\hline $50-59$ & 2,004 & 27.43 & 1,615 & 389 & 921 & 669 & 283 & 104 & 27 & $p<.001$ \\
\hline $60-69$ & 3,218 & 44.05 & 2,661 & 557 & 866 & 1,169 & 707 & 338 & 138 & \\
\hline$\geq 70$ & 2,083 & 28.51 & 1,670 & 413 & 406 & 686 & 590 & 288 & 113 & \\
\hline Education & & & & & & & & & & $\mathrm{p}<.001$ \\
\hline Less than High School & 1,705 & 23.34 & 1,285 & 420 & 367 & 537 & 435 & 238 & 128 & \\
\hline High School/GED & 2,410 & 32.99 & 2,007 & 403 & 700 & 850 & 537 & 245 & 78 & \\
\hline Some College or more & 3,190 & 43.67 & 2,654 & 536 & 1,126 & 1,137 & 608 & 247 & 72 & \\
\hline Median AVGEARN_LIFETIME ${ }^{\dagger}$ & $\$ 19,410$ & & $\$ 19,488$ & $\$ 19,138$ & & & & & & \\
\hline Inter-quartile Range AVGEARN_LIFETIME & $\$ 20,235$ & & & & & & & & & \\
\hline
\end{tabular}

${ }^{\dagger}$ AVGEARN_LIFETIME = Average annual lifetime earnings (age 20-50) which are adjusted using the CPI-U to account for inflation.

reporting childhood financial hardship and those not reporting childhood financial hardship did not change substantially $(\exp (\beta)=1.10 ; \mathrm{CI}: 1.04,1.16)$. After adjusting for educational attainment, the expected number of chronic conditions for those reporting childhood financial hardship was reduced to 1.08 (CI: $1.02,1.14)$ times greater than for those not reporting childhood financial hardship (See Table 3, models 1-3, Poisson portion).

\section{Multivariable analysis: lifetime earnings and multimorbidity}

The logistic portion of the ZIP models showed that lifetime earnings and the absence of morbidity were only associated in the unadjusted model $(\exp (\beta)=.55$; CI: .28, .91; see Table 4, models 4-6, logistic portion). The Poisson portion of the unadjusted ZIP model showed a $7 \%$ decrease in the expected number of chronic conditions for each $\$ 10,000$ increase in average annual lifetime earnings (see Table 4, model 4). After adjusting for gender, age, and race the percent decrease was unchanged at $7 \%$. However, after adjusting for educational attainment the percent decrease in the expected number of chronic conditions was reduced to $5 \%$ for each $\$ 10,000$ increase in average annual earnings (see Table 4, model 6, Poisson portion).
Multivariable analysis: childhood financial hardship and lifetime earnings mutually adjusted and interaction term added

Including childhood financial hardship and lifetime earnings into the ZIP model (see Table 5, model 7) showed a slight change in the childhood financial hardship rate ratio from the fully adjusted model (see Table 3 , model 3) of 1.08 to 1.07 , but the rate ratio for lifetime earnings from the fully adjusted model (see Table 4, model 6) was unchanged (see Table 5, model 7). The childhood financial hardship $\times$ average annual lifetime earnings interaction term was statistically significant $(\exp (\beta)=.95 ; \mathrm{CI}=.91, .99)$; and with the inclusion of this interaction term the rate ratio for childhood financial hardship increased $(\exp (\beta)=1.19 ; \mathrm{CI}: 1.07,1.32)$ and the rate ratio for lifetime earnings changed by $2 \%$ $(\exp (\beta)=.97 ; \mathrm{CI}=.94, .99 ;$ see Table 5, model 8).

\section{Discussion}

This study investigated the association among childhood financial hardship, lifetime earnings, and multimorbidity in a sample of older adults. Our findings revealed that after controlling for socioeconomic and demographic characteristics, childhood financial hardship was positively associated with a higher number of the chronic conditions. This suggests that over and above the 
Table 2 Unadjusted rate ratios of bivariate associations between the demographic and socioeconomic variables and multimorbidity

\begin{tabular}{|c|c|}
\hline & Multimorbidity \\
\hline \multicolumn{2}{|l|}{ Gender } \\
\hline Female & 1.00 \\
\hline Male & $\begin{array}{c}1.08^{* *} \\
(1.03,1.12)\end{array}$ \\
\hline \multicolumn{2}{|l|}{ Race } \\
\hline White & 1.00 \\
\hline Non-white & $\begin{array}{c}1.21^{* * *} \\
(1.15,1.26)\end{array}$ \\
\hline \multicolumn{2}{|l|}{ Hispanic Ethnicity } \\
\hline Hispanic & $\begin{array}{c}.94 \\
(.87,1.00)\end{array}$ \\
\hline Non-Hispanic & 1.00 \\
\hline \multicolumn{2}{|l|}{ Age } \\
\hline $50-59$ & 1.00 \\
\hline $60-69$ & $\begin{array}{c}1.56^{* * *} \\
(1.47,1.65)\end{array}$ \\
\hline$\geq 70$ & $\begin{array}{c}1.85^{* * *} \\
(1.74,1.96)\end{array}$ \\
\hline \multicolumn{2}{|l|}{ Education } \\
\hline Less than High School & $\begin{array}{c}1.46^{* * *} \\
(1.39,1.53)\end{array}$ \\
\hline High School/GED & $\begin{array}{c}1.16^{* * *} \\
(1.11,1.22)\end{array}$ \\
\hline Some College or more & 1.00 \\
\hline
\end{tabular}

$\mathrm{p}<.05 ;{ }^{* *} \mathrm{p}<.01 ;{ }^{* * *} \mathrm{p}<.001$.

influence of age, race, and educational attainment, childhood financial hardship exerts an influence on the multimorbidity of the six chronic conditions measured in this study for older adults. Our findings also indicate that lifetime earnings was negatively associated with multimorbidity, although the noted association was relatively small. In particular, we showed that as the average annual income during young and middle adulthood increases by $\$ 10,000$ the number of chronic conditions (as measured in this study) decreases by $5 \%$. Additionally, when we included both childhood financial hardship and lifetime earnings in our models, the association between lifetime earnings and multimorbidity remained unchanged and the association between childhood financial hardship and multimorbidity was only slightly reduced. However, our tests of interactions revealed that lifetime earnings significantly modifies the relationship between childhood financial hardship and multimorbidity. This suggests that the influence of financial hardship in childhood on subsequent multimorbidity may be altered by earnings occurring in young and middle adulthood. More specifically, our findings showed that for older adults experiencing childhood financial hardship an increase by $\$ 10,000$ in average annual earnings reduces the expected number of chronic conditions by
Table 3 Unadjusted and adjusted exponentiated parameter estimates and confidence intervals for the zero-inflated Poisson regression models testing the association between childhood financial hardship and multimorbidity

\begin{tabular}{lrrr}
\hline Logistic portion of the ZIP model & & & \\
& Model 1 & Model 2 & Model 3 \\
\hline Childhood financial hardship $^{\dagger}$ & .30 & .39 & .43 \\
& $(.004,46.63)$ & $(.10,1.52)$ & $(.11,1.60)$ \\
Gender & .92 & 1.00 \\
(female is reference) & $(.46,1.87)$ & $(.49,2.04)$ \\
Age & $.77^{* * *}$ & $.78^{* * *}$ \\
& $(.69, .82)$ & $(.68, .82)$ \\
Race & 4.03 & .28 \\
(white is reference) & $(.74,22.01)$ & $(.05,1.22)$ \\
Educational Attainment & & \\
(less than high school) & & \\
$\quad$ High School/GED & & $(.74,4.34)$ \\
\multicolumn{1}{c}{ Some College or more } & & .79 \\
& & $(.29,2.16)$
\end{tabular}

Poisson Portion of the ZIP model

\begin{tabular}{lrrr} 
& Model 1 & Model 2 & Model 3 \\
\hline Childhood financial hardship $^{\dagger}$ & $1.11^{* *}$ & $1.10^{* * *}$ & $1.08^{* *}$ \\
& $(1.04,1.19)$ & $(1.04,1.16)$ & $(1.02,1.14)$ \\
Gender & .36 & .41 \\
(female is reference) & $(.10,1.39)$ & $(.11,1.50)$ \\
Age & $1.02^{* * *}$ & $1.02^{* * *}$ \\
& $(1.02,1.03)$ & $(1.02,1.03)$ \\
Race & .73 & 1.14 \\
(white is reference group) & $(.37,1.45)$ & $(.56,2.32)$ \\
Educational Attainment & & \\
(less than high school) & & \\
$\quad$ High School/GED & & $(.05, .93)$ \\
\multicolumn{1}{c}{ Some College or more } & & 1.52 \\
& & $(.63,3.67)$ \\
\hline
\end{tabular}

$\mathrm{p}<.05 ;{ }^{* *} \mathrm{p}<.01 ;{ }^{* * *} \mathrm{p}<.001 ;{ }^{\dagger}$ Childhood financial hardship was measured by a question, "While you were growing up, before age 16, did financial difficulties ever cause you or your family to move to a different place?".

$5 \%$. Lastly, although we were primarily interested in determining the association among childhood financial hardship, lifetime earnings, and multimorbidity over and above the influence of other socioeconomic indicators such as educational attainment, it should be noted that increasing education was not consistently associated with an increase in the count of the six chronic conditions in this study. In particular, educational attainment was not associated with the absence of morbidity; and when compared to the less than high school group, only the high school/GED category showed a protective association with multimorbidity.

We evaluated our hypotheses using ZIP regression; and, the benefit of a ZIP modeling approach is the simultaneous estimation of factors associated with multimorbidity and the absence of morbidity. In fully adjusted models, childhood financial hardship was not 
Table 4 Unadjusted and adjusted exponentiated parameter estimates and confidence intervals for the zero-inflated Poisson regression models testing the association between lifetime earnings and multimorbidity

\begin{tabular}{|c|c|c|c|}
\hline \multicolumn{4}{|l|}{ Logistic portion of the ZIP model } \\
\hline & Model 4 & Model 5 & Model 6 \\
\hline Lifetime Earnings ${ }^{\S}$ & $\begin{array}{r}.55^{*} \\
(.28, .91)\end{array}$ & $\begin{array}{r}1.08 \\
(.81,1.42)\end{array}$ & $\begin{array}{r}1.10 \\
(.80,1.51)\end{array}$ \\
\hline Gender & & $\begin{array}{r}1.15 \\
(.50,2.64)\end{array}$ & $\begin{array}{r}1.16 \\
(.50,2.71)\end{array}$ \\
\hline Age & & $\begin{array}{r}.77^{* * *} \\
(.67, .83)\end{array}$ & $\begin{array}{r}.76^{* * *} \\
(.66, .82)\end{array}$ \\
\hline $\begin{array}{l}\text { Race } \\
\text { (white is reference) }\end{array}$ & & $\begin{array}{r}.35 \\
(.08,1.45)\end{array}$ & $\begin{array}{r}.32 \\
(.08,1.37)\end{array}$ \\
\hline \multicolumn{4}{|l|}{$\begin{array}{l}\text { Educational Attainment } \\
\text { (less than high school is reference) }\end{array}$} \\
\hline High School/GED & & & $\begin{array}{r}2.03 \\
(.73,5.69)\end{array}$ \\
\hline Some College or more & & & $\begin{array}{r}.84 \\
(.27,2.55)\end{array}$ \\
\hline \multicolumn{4}{|l|}{ Poisson Portion of the ZIP model } \\
\hline & Model 4 & Model 5 & Model 6 \\
\hline lifetime earnings $^{\S}$ & $\begin{aligned} .93 * * * \\
(.91, .95)\end{aligned}$ & $\begin{array}{r}.93^{* * *} \\
(.91, .95)\end{array}$ & $\begin{array}{r}.95^{* * *} \\
(.93, .98)\end{array}$ \\
\hline Gender & & $\begin{array}{r}1.14^{* * *} \\
(1.08,1.20)\end{array}$ & $\begin{array}{r}1.11^{* * *} \\
(1.05,1.17)\end{array}$ \\
\hline Age & & $\begin{array}{r}1.02^{* * *} \\
(1.02,1.03)\end{array}$ & $\begin{array}{r}1.02^{* * *} \\
(1.02,1.03)\end{array}$ \\
\hline $\begin{array}{l}\text { Race } \\
\text { (white is reference) }\end{array}$ & & $\begin{array}{r}1.22 \\
(.54,2.78)\end{array}$ & $\begin{array}{r}1.23 \\
(.53,2.83)\end{array}$ \\
\hline \multicolumn{4}{|l|}{$\begin{array}{l}\text { Educational Attainment } \\
\text { (less than high school is reference) }\end{array}$} \\
\hline High School/GED & & & $\begin{array}{r}.26 \\
(.06,1.06)\end{array}$ \\
\hline Some College or more & & & $\begin{array}{r}1.76 \\
(.63,4.89)\end{array}$ \\
\hline
\end{tabular}

$\mathrm{p}<.05 ;{ }^{* *} \mathrm{p}<.01 ;{ }^{* * *} \mathrm{p}<.001{ }^{\S}$ Lifetime earnings was operationalized as average annual income from 1951 up to age 50 of the respondent CPI-U adjusted.

associated with the absence of morbidity and lifetime earnings was only associated with the absence of morbidity in unadjusted models. Consistent with the literature, the logistic portion of our ZIP models showed that age was strongly negatively associated with the absence of morbidity [37]. Lastly, the widest confidence intervals were noted in the logistic portion of the childhood financial hardship ZIP models. This may indicate poor model fit and suggests that the potential socioeconomic and demographic factors associated with determining the number of diseases (of those measured in this study) might be substantively different from the factors associated with determining the absence of morbidity.

The lack of an association between the several indicators of socioeconomic circumstances in this study (i.e. childhood financial hardship, lifetime earnings, and educational attainment) and demographic characteristics
Table 5 Fully adjusted exponentiated parameter estimates and confidence intervals for zero-inflated Poisson regression models testing the association among childhood financial hardship, lifetime earnings, and multimorbidity, and the interaction between childhood financial hardship and lifetime earnings

\begin{tabular}{|c|c|c|}
\hline \multicolumn{3}{|l|}{ Logistic portion of the ZIP model } \\
\hline & Model 7 & Model 8 \\
\hline Childhood financial hardship $^{\dagger}$ & $\begin{array}{r}.40 \\
(.09 \\
1.71)\end{array}$ & $\begin{array}{r}.27 \\
(.04, \\
2.05)\end{array}$ \\
\hline $\begin{array}{l}\text { Gender } \\
\text { (female is reference) }\end{array}$ & $\begin{array}{c}1.16 \\
(.50 \\
2.70)\end{array}$ & $\begin{array}{r}1.05 \\
(.47 \\
2.33)\end{array}$ \\
\hline Age & $\begin{array}{r}.76^{* * *} \\
(.67, .82)\end{array}$ & $\begin{array}{r}.75^{* * *} \\
(.66, .81)\end{array}$ \\
\hline $\begin{array}{l}\text { Race } \\
\text { (white is reference) }\end{array}$ & $\begin{array}{r}.34 \\
(.10 \\
1.23)\end{array}$ & $\begin{array}{r}.34 \\
(.10 \\
1.15)\end{array}$ \\
\hline \multicolumn{3}{|l|}{$\begin{array}{l}\text { Educational Attainment (less than high school } \\
\text { reference) }\end{array}$} \\
\hline High School/GED & $\begin{array}{c}1.91 \\
(.71 \\
5.11)\end{array}$ & $\begin{array}{r}1.49 \\
(.61, \\
3.67)\end{array}$ \\
\hline Some College or more & $\begin{array}{r}.67 \\
(.24 \\
1.89)\end{array}$ & $\begin{array}{r}.62 \\
(.22 \\
1.70)\end{array}$ \\
\hline Lifetime Earnings ${ }^{\S}$ & $\begin{array}{c}1.03 \\
(.73 \\
1.42)\end{array}$ & $\begin{array}{r}1.06 \\
(.77 \\
1.44)\end{array}$ \\
\hline Childhood financial hardship X Lifetime earnings & & $\begin{array}{r}1.35 \\
(.35 \\
3.36)\end{array}$ \\
\hline
\end{tabular}

Poisson Portion of the ZIP model

\begin{tabular}{lrr} 
& Model 7 & Model 8 \\
\hline Childhood financial hardship $^{+}$ & $1.07^{*}$ & $1.19^{* * *}$ \\
& $(1.01$, & $(1.07$, \\
& $1.13)$ & $1.32)$ \\
Gender & .41 & .25 \\
(female is reference) & $(.10$, & $(.03$, \\
& $1.74)$ & $1.83)$ \\
Age & $1.02^{* * *}$ & $1.02^{* * *}$ \\
& $(1.02$, & $(1.02$, \\
& $1.03)$ & $1.03)$ \\
Race & 1.23 & 1.12 \\
(white is reference group) & $(.53$, & $(.51$, \\
& $2.82)$ & $2.46)$
\end{tabular}

Educational Attainment (less than high school is reference)

$\begin{array}{lrr}\text { High School/GED } & .27^{*} & .27^{*} \\ & (.08, .95) & (.08, .89) \\ \text { Some College or more } & 1.66 & 1.49 \\ & (.62, & (.61, \\ & 4.41) & 3.67) \\ & .95^{* * *} & .97^{*} \\ & (.93, .97) & (.94, .99) \\ & & .95^{*} \\ \text { ldime Earnings } & & (.91, .99) \\ & & \end{array}$

${ }^{*} \mathrm{p}<.05 ; * * \mathrm{p}<.01 ; * * * \mathrm{p}<.001 ;{ }^{\dagger}$ Childhood financial hardship was measured by a question, "While you were growing up, before age 16, did financial difficulties ever cause you or your family to move to a different place?" ${ }^{\S}$ Lifetime Earnings was operationalized as average annual income from 1951 up to age 50 of the respondent CPI- $U$ adjusted 
(i.e. race and gender) and the absence of morbidity was unexpected. Research has shown a negative association between socioeconomic status and morbidity [38,39] and multimorbidity[40,41]; and studies on successful aging (where one component is the absence or low risk of morbidity[42]) have shown that childhood and mid-life socioeconomic circumstances[43], and the stability of financial resources[44] were positively associated with the absence of morbidity in older adults. However, the evidence on the association between socioeconomic factors and successful aging is equivocal[45-47]. It has also been suggested that age effects on self-reported morbidity may overshadow socioeconomic effects[48]. Not surprising, our results show an independent association between the absence of morbidity and age, even when childhood financial hardship and lifetime earnings are included in the model. Demographic characteristics[48] and psychosocial and behavioral factors[49] across the lifecourse may prove more important than socioeconomic factors in determining the absence of morbidity; however, the influence of lifecourse socioeconomic factors on the absence of morbidity requires further exploration to fully elucidate their role in successful aging in general and the absence of morbidity in particular among older adults.

\section{Childhood socioeconomic condition and adult health}

Financial and economic circumstances occurring in childhood and throughout the lifecourse have been shown to affect adult health outcomes [50]. Research shows that antecedents to the socioeconomic gradient in adult health can be seen in the socioeconomic environment in childhood [51]. As such, the childhood environment can, 'cast long shadows forward' on future health outcomes [52]; that is, the financial and economic circumstances occurring and accumulating throughout the lifecourse can determine and influence the health trajectory of the individual $[53,54]$.

Additionally, it has been suggested that many chronic diseases share common risk factors [55]. In particular, current low socioeconomic status and disadvantage accumulated across the lifecourse have been shown to be significant pathways to many chronic conditions [25,56]; and, socio-environmental factors experienced at various stages throughout the lifecourse can differentially impact disease etiology [57]. So, even though chronic diseases have long latency periods, research has consistently shown that for many chronic conditions adult and childhood socioeconomic factors can have a considerable impact on health outcomes $[58,59]$. Our results are consistent with these findings. In particular, our results show that an expanded notion of SES that includes hardships during childhood and earnings throughout adulthood may also uncover possible associations between socioeconomic conditions and adult health. Our findings also show that a possible modifier of the relationship between childhood financial conditions and the number of adult chronic conditions that deserves further attention is earnings during young and middle adulthood.

\section{Limitations}

There are limitations to the present study. First, respondents in the HRS were asked to recall childhood financial hardship experiences; as a result, the measures of childhood financial hardship may be subject to recall bias. Second, our sample only included those individuals who provided permission for their social security records to be linked to their HRS records potentially introducing sample selection bias. However, it has been shown that the HRS respondents who grant permission for their social security were not very much different from those who did not [60]. In addition, the social security data linked to the HRS is capped at the taxable maximum for a given year and only includes earnings subject to Social Security deduction. Next, the literature remains inconsistent in defining multimorbidity [61,62]; for example, some studies define multimorbidity as the count of two or more chronic conditions, [40] others use a combination of specific diseases, and still others use a simple count of chronic conditions reported or obtained from medical records [63,64]. As a result, little guidance is provided in selecting a measure for multimorbidity and the specific diseases such a measure should contain. However, the chronic diseases selected for the present study are consistent with those of other studies of multimorbidity among older adults $[21,65]$. Lastly, our study is cross-sectional so causal inferences cannot be definitively made regarding the associations noted.

\section{Conclusions}

Multimorbidity has considerable implications for healthrelated research, health care, and many government systems (e.g. Medicare, Medicaid, and Veterans Administration). Due to the single disease focus in research and health care[66,67], we know relatively little about the correlates of multimorbidity $[68,69]$. Yet, health care models on the delivery of clinical services for the elderly with multiple chronic conditions have recently been introduced highlighting the impact the growing problem of multimorbidity has on health care delivery [70,71]. However, we know little about the factors that are associated with the various combinations of morbidity experienced by older adults, and such knowledge could potentially improve care and delay mortality for many managing multiple chronic conditions [72]. Additional research focused on the specific socioeconomic factors associated with multimorbidity across the lifecourse can also be used to inform the development of appropriate interventions that target socioeconomic groups at greatest risk 
for multimorbidity before they enter the health care system. In particular, interventions that target specific socioeconomic pathways might prove useful in helping reduce the burden of multimorbidity; more specifically, interventions that focus on material resources such as reducing hardships during childhood and increasing earnings throughout young and middle adulthood may have a substantial impact on prevention efforts[73] with those at risk for various combinations of chronic disease multimorbidity.

\section{Acknowledgements}

None

\section{Author details}

'Center for Community Based Research, Dana-Farber Cancer Institute, 450 Brookline Ave, Boston, MA, 02215 USA. ${ }^{2}$ Department of Society, Human Development, and Health, Harvard School of Public Health, 677 Huntington Ave, Boston, MA, 02115 USA. ${ }^{3}$ Department of Biostatistics and Computational Biology, Dana-Farber Cancer Institute, 450 Brookline Ave, Boston, MA, 02215 USA. ${ }^{4}$ Department of Biostatistics, Harvard School of Public Health, 677 Huntington Ave, Boston, MA, 02115 USA.

\section{Authors' contributions}

RDT-S, YL, GS, and SVS conceived of the study; RDT-S and YL developed the analysis plan and performed the statistical analysis; RDT-S, YL, GS, and SVS interpreted the results; RDT-S wrote the first draft of the manuscript. RDT-S, $Y L, G S$, and SVS edited the manuscript. All authors read and approved the final manuscript.

\section{Competing interests}

The authors declare that they have no competing interests.

Received: 6 December 2010 Accepted: 14 May 2011

Published: 14 May 2011

\section{References}

1. Guralnik JM, LaCroix AZ, Everett DF, Kovar MG: Aging in the eighties: The prevalence of comorbidity and its association with disability. Advance data from vital and health statistics National Center for Health Statistics. Hyattsville, MD; 1989, No. 170.

2. Wolff $J$, Starfield B, Anderson G: Prevalence, expenditures, and complications of multiple chronic conditions in the elderly. Arch Intern Med 2002, 162:2269-2276.

3. Knottnerus JA, Metsemakers J, Hoppener P, Limonard C: Chronic illness in the community and the concept of 'social prevalence'. Fam Pract 1992, 9:15-21.

4. van den Akker M, Buntinx F, Metsemakers JF, Roos S, Knottnerus JA: Multimorbidity in general practice: prevalence, incidence, and determinants of co-occurring chronic and recurrent diseases. J Clin Epidemiol 1998, 51:367-375.

5. van den Akker M, Buntinx F, Metsemakers JF, Knottnerus JA: Marginal impact of psychosocial factors on multimorbidity: results of an explorative nested case-control study. Soc Sci Med 2000, 50:1679-1693.

6. Martini EM, Garrett N, Lindquist T, Isham GJ: The boomers are coming: a total cost of care model of the impact of population aging on health care costs in the United States by Major Practice Category. Health Serv Res 2007, 42:201-218

7. Rice DP, Fineman N: Economic implications of increased longevity in the United States. Annu Rev Public Health 2004, 25:457-473.

8. Eyre H, Kahn R, Robertson RM, Clark NG, Doyle C, Hong Y, Gansler T, Glynn T, Smith RA, Taubert K, Thun MJ, American Cancer Society, American Diabetes Association, American Heart Association: Preventing cancer, cardiovascular disease, and diabetes: a common agenda for the American Cancer Society, the American Diabetes Association, and the American Heart Association. Circulation 2004, 109:3244-3255.
9. Gijsen R, Hoeymans N, Schellevis FG, Ruwaard D, Satariano WA, van den Bos GAM: Causes and consequences of comorbidity: A review. J Clin Epidemiol 2001, 54:661-674

10. Wadsworth MEJ, Kuh DJL: Childhood influences on adult health: a review of recent work from the British 1946 national birth cohort study, the MRC National Survey of Health and Development. Paediatric and Perinatal Epidemiology 1997, 11:2-20.

11. Kaplan GA, Salonen JT: Socioeconomic conditions in childhood and ischaemic heart disease during middle age. BMJ 1990, 301:1121-1123.

12. Lawlor DA, Ronalds G, Macintyre S, Clark H, Leon DA: Family socioeconomic position at birth and future cardiovascular disease risk: findings from the Aberdeen Children of the 1950s cohort study. Am J Public Health 2006, 96:1271-1277.

13. Maty SC, Lynch JW, Raghunathan TE, Kaplan GA: Childhood socioeconomic position, gender, adult body mass index, and incidence of type 2 diabetes mellitus over 34 years in the Alameda County Study. Am J Public Health 2008, 98:1486-1494.

14. Smith GD, Hart C, Blane D, Hole D: Adverse socioeconomic conditions in childhood and cause specific adult mortality: prospective observational study. BMJ 1998, 316:1631-1635.

15. Bennett GG, Wolin KY, James SA: Lifecourse socioeconomic position and weight change among blacks: The Pitt County study. Obesity (Silver Spring) 2007, 15:172-181.

16. Lundberg $\mathrm{O}$ : The impact of childhood living conditions on illness and mortality in adulthood. Soc Sci Med 1993, 36:1047-1052.

17. Lundberg $\mathrm{O}$ : Childhood conditions, sense of coherence, social class and adult ill health: exploring their theoretical and empirical relations. Soc Sci Med 1997, 44:821-831.

18. Moody-Ayers S, Lindquist K, Sen S, Covinsky KE: Childhood social and economic well-being and health in older age. Am J Epidemiol 2007, 166:1059-1067.

19. Hatch SL: Conceptualizing and identifying cumulative adversity and protective resources: implications for understanding health inequalities. J Gerontol B Psychol Sci Soc Sci 2005, 60(Spec No 2):130-134.

20. Hungerford TL: The persistence of hardship over the lifecourse. Research on Aging 2007, 29:491-511.

21. Kahn JR, Fazio EM: Economic status over the life course and racial disparities in health. J Gerontol B Psychol Sci Soc Sci 2005, 60(Spec No 2):76-84.

22. Davey Smith G: Socioeconomic differentials. In A life course approach to chronic disease epidemiology. Edited by: Kuh D, Ben-Shlomo Y. Oxford: Oxford Medical Publications; 2001:.

23. Smith GD, Hart C, Blane D, Gillis C, Hawthorne V: Lifetime socioeconomic position and mortality: prospective observational study. BMJ 1997, 314:547-552

24. Davey Smith G, Ben-Shlomo Y, Lynch J: Life course approaches to inequalities in coronary heart disease risk. In Stress and the heart: Psychosocial pathways to coronary heart disease. Edited by: Stansfeld SA, Marmot MG. London: BMJ Books; 2002:

25. Gold R, Michael YL, Whitlock EP, Hubbell FA, Mason ED, Rodriguez BL, Safford MM, Sarto GE: Race/ethnicity, socioeconomic status, and lifetime morbidity burden in the women's health initiative: a cross-sectional analysis. J Womens Health (Larchmt) 2006, 15:1161-1173.

26. Melchior M, Lert F, Martin M, Ville I: Socioeconomic position in childhood and in adulthood and functional limitations in midlife: Data from a nationally-representative survey of French men and women. Soc Sci Med 2006, 63:2813-2824.

27. Singh-Manoux A, Ferrie JE, Chandola T, Marmot M: Socioeconomic trajectories across the life course and health outcomes in midlife: evidence for the accumulation hypothesis? Int J Epidemiol 2004, 33:1072-1079.

28. University of Michigan: Health and Retirement Study (HRS2004) public use dataset. Produced and distributed by the University of Michigan with funding from the National Institute on Aging (grant number NIA U01AG009749). Ann Arbor, Ml; 2004.

29. National Institute on Aging: Growing Old in America: The Health and Retirement Study. National Institutes of Health. Washington, DC; 2007.

30. Cristia JP: The empirical relationship between lifetime earnings and mortality. Congressional Budget Office. Washington, D.C; 2007, Working Paper Series. 2007-11.

31. U.S. Department of Labor: Consumer Price Index. Bureau of Labor Statistics. 
32. Galobardes B, Lynch J, Smith GD: Measuring socioeconomic position in health research. Br Med Bull 2007, 81-82:21-37.

33. Cameron AC, Trivedi PK: Regression Analysis of Count Data. New York: Cambridge University Press; 1998.

34. Tin A: Modeling zero-inflated count data with underdispersion and overdispersion. SAS Global Forum Proceedings 2008, Paper 372-2008.

35. Lambert D: Zero-inflated Poisson regression, with an applicationto defects in manufacturing. Technometrics 1992, 34:1-14.

36. Knol MJ, van der Tweel I, Grobbee DE, Numans ME, Geerlings MI: Estimating interaction on an additive scale between continuous determinants in a logistic regression model. Int J Epidemiol 2007, 36:1111-1118

37. Crimmins EM: Trends in the health of the elderly. Annu Rev Public Health 2004, 25:79-98.

38. House JS, Lepkowski JM, Kinney AM, Mero RP, Kessler RC, Herzog AR: The social stratification of aging and health. J Health Soc Behav 1994, 35:213-234.

39. Huisman M, Kunst AE, Mackenbach JP: Socioeconomic inequalities in morbidity among the elderly; a European overview. Soc Sci Med 2003, 57:861-873.

40. Marengoni A, Winblad B, Karp A, Fratiglioni L: Prevalence of chronic diseases and multimorbidity among the elderly population in Sweden. Am J Public Health 2008, 98:4-6.

41. Nagel G, Peter R, Braig S, Hermann S, Rohrmann S, Linseisen J: The impact of education on risk factors and the occurrence of multimorbidity in the EPIC-Heidelberg cohort. BMC Public Health 2008, 8:384, 384.

42. Rowe JW, Kahn RL: Successful aging. Gerontologist 1997, 37:433-440.

43. Britton A, Shipley M, Singh-Manoux A, Marmot MG: Successful aging: the contribution of early-life and midlife risk factors. J Am Geriatr Soc 2008, 56:1098-1105.

44. Burke GL, Arnold AM, Bild DE, Cushman M, Fried LP, Newman A, Nunn C, Robbins J: Factors associated with healthy aging: the cardiovascular health study. J Am Geriatr Soc 2001, 49:254-262.

45. Reed DM, Foley DJ, White LR, Heimovitz H, Burchfiel CM, Masaki K: Predictors of healthy aging in men with high life expectancies. Am J Public Health 1998, 88:1463-1468.

46. Depp CA, Jeste DV: Definitions and predictors of successful aging: a comprehensive review of larger quantitative studies. Am J Geriatr Psychiatry 2006, 14:6-20.

47. Roos NP, Havens B: Predictors of successful aging: a twelve-year study of Manitoba elderly. Am J Public Health 1991, 81:63-68.

48. Asthana S, Gibson A, Moon G, Brigham P, Dicker J: The demographic and social class basis of inequality in self reported morbidity: an exploration using the Health Survey for England. J Epidemiol Community Health 2004, 58:303-307.

49. Peel NM, McClure RJ, Bartlett HP: Behavioral determinants of healthy aging. Am J Prev Med 2005, 28:298-304.

50. Galobardes B, Davey Smith G, Jeffreys M, McCarron P: Childhood socioeconomic circumstances predict specific causes of death in adulthood: the Glasgow student cohort study. J Epidemiol Community Health 2006, 60:527-529.

51. Case A, Lubotsky D, Paxson C: Economic Status and Health in Childhood: The Origins of the Gradient. American Economic Review 2002, 92:1308-1334.

52. Graham H, Power C: Childhood disadvantage and adult health: a lifecourse framework. Health Development Agency. London; 2004.

53. Lawlor DA, Ebrahim S, vey Smith G: Adverse socioeconomic position across the lifecourse increases coronary heart disease risk cumulatively: findings from the British women's heart and health study. J Epidemiol Community Health 2005, 59:785-793.

54. Lynch JW, Kaplan GA, Shema SJ: Cumulative impact of sustained economic hardship on physical, cognitive, psychological, and social functioning. N Engl J Med 1997, 337:1889-1895.

55. Cassel J: The contribution of the social environment to host resistance: the fourth Wade Hamptom Frost lecture. Am J Epidemiol 1976, 104:107-123.

56. Power $C$, Hertzman $C$ : Social and biological pathways linking early life and adult disease. Br Med Bull 1997, 53:210-221.

57. Lynch J, Davey Smith G: A lifecourse approach to chronic disease epidemiology. Annu Rev Public Health 2005, 36:1-35.
58. Galobardes B, Smith GD, Lynch JW: Systematic review of the influence of childhood socioeconomic circumstances on risk for cardiovascular disease in adulthood. Ann Epidemiol 2006, 16:91-104.

59. Pollitt RA, Rose KM, Kaufman JS: Evaluating the evidence for models of life course socioeconomic factors and cardiovascular outcomes: a systematic review. BMC public health 2005, 5:7.

60. Haider S, Salon G: Nonrandom selection in the HRS Social Security Earnings Sample. 2000, Paper 00-01. RAND Labor and Population Program.

61. Valderas JM, Starfield B, Sibbald B, Salisbury C, Roland M: Defining comorbidity: Implications for understanding health and health services. Annals of Family Medicine 2009, 7:357-363.

62. van den Akker M, Buntinx F, Knottnerus JA: Comorbidity or multimorbidity: what's in a name? A review of the literature. European Journal of General Practice 1996, 2:65-70.

63. de Groot V, Beckerman H, Lankhorst GJ, Bouter LM: How to measure comorbidity. a critical review of available methods. J Clin Epidemiol 2003, 56:221-229.

64. Schoenberg NE, Kim H, Edwards W, Fleming ST: Burden of common multiple-morbidity constellations on out-of-pocket medical expenditures among older adults. Gerontologist 2007, 47:423-437.

65. Fillenbaum GG, Pieper CF, Cohen HJ, Cornoni-Huntley JC, Guralnik JM: Comorbidity of five chronic health conditions in elderly community residents: determinants and impact on mortality. J Gerontol A Biol Sci Med Sci 2000, 55:M84-M89.

66. Tinetti ME, Bogardus ST Jr, Agostini JV: Potential pitfalls of disease-specific guidelines for patients with multiple conditions. N Engl J Med 2004, 351:2870-2874

67. Starfield B: Threads and yarns: Weaving the tapestry of comorbidity. Annals of Family Medicine 2006, 4:101-103.

68. van den Akker M, Vos R, Knottnerus JA: In an exploratory prospective study on multimorbidity general and disease-related susceptibility could be distinguished. J Clin Epidemiol 2006, 59:934-939.

69. Fortin M, Bravo G, Hudon C, Lapointe L, Dubois MF, Almirall J: Psychological distress and multimorbidity in primary care. Annals of Family Medicine 2006, 4:417-422.

70. Thiem U, Theile G, Junius-Walker U, Holt S, Thurmann P, Hinrichs T, Platen P, Diederichs C, Berger K, Hodek JM, Greiner W, Berkemeyer S, Pientka L, Trampisch HJ: Prerequisites for a new health care model for elderly people with multimorbidity: The PRISCUS research consortium. Z Gerontol Geriatr 2010

71. Boyd C, Leff B, Weiss C, Wolff J, Clark R, Richards T: Clarifying multimorbidity to improve targeting and delivery of clinical services for Medicaid populations.[http://www.chcs.org/publications3960/ publications_show.htm?doc_id=1261201].

72. Fortin M, Soubhi H, Hudon C, Bayliss EA, van den Akker M: Multimorbidity's many challenges. BMJ 2007, 334:1016-1017.

73. Williams DR, Costa MV, Odunlami AO, Mohammed SA: Moving upstream: How interventions that address the social determinants of health can improve health and reduce disparities. Journal of Public Health Management Practice 2008, 14(Suppl):S8-S17.

\section{Pre-publication history}

The pre-publication history for this paper can be accessed here: http://www.biomedcentral.com/1471-2458/11/313/prepub

\section{doi:10.1186/1471-2458-11-313}

Cite this article as: Tucker-Seeley et al.: Lifecourse socioeconomic circumstances and multimorbidity among older adults. BMC Public Health 2011 11:313. 